\title{
Influência das configurações organizacionais sobre valores no trabalho e preferências por recompensa*
}

\author{
Isabel de Sá Affonso da Costa** \\ Denise Medeiros Ribeiro Salles*** \\ Joaquim Rubens Fontes Filho****
}

SumÁRIo: 1. Introdução; 2. Organizações: públicas, privadas e híbridas; 3. Valores, motivos e preferências; 4 . A pesquisa; 5 . Conclusões.

Summary: 1. Introduction; 2. Organisations: public, private and hybrid; 3. Values, reasons and preferences; 4 . The research; 5 . Conclusions.

PaLAVRAs-CHAVE: valores; recompensas; configurações organizacionais; organizações híbridas.

KEY woRDs: values; rewards; organizational types; hybrid organizations.

$\mathrm{O}$ artigo tem como objetivo identificar as similaridades e diferenças nos valores relacionados ao trabalho e preferências por recompensa entre diferentes configurações organizacionais, especificamente organizações privadas, públicas e de contextos mistos ou híbridos. Tendo como base pesquisa realizada no Brasil por Tamayo e Gondim (1996) sobre os valores e nos Estados Unidos por Wittmer (1991) sobre preferências por recompensa, as variáveis de interesse relacionaram-se a quatro

\footnotetext{
* Artigo recebido em jun. 2010 e aceito em ago. 2010.

** Doutora em administração pela Escola Brasileira de Administração Pública e de Empresas da Fundação Getulio Vargas (Ebape/FGV). Professora do Programa de Mestrado em Administração e Desenvolvimento Empresarial/Universidade Estácio de Sá. Endereço: Av. Presidente Vargas, 642/22o andar - Centro - CEP 20071-001 — Rio de Janeiro, RJ, Brasil. E-mail: isabel.costa@ estacio.br.

*** Mestre em administração pela Universidade Federal Fluminense (UFF). Candidata ao doutorado pela Escola Brasileira de Administração Pública e de Empresas da Fundação Getulio Vargas (Ebape/FGV). Professora da Universidade Federal Fluminense (UFF). Endereço: Praia de Botafogo, 190/sala 502 - CEP 22250-900 — Rio de Janeiro, RJ, Brasil. E-mail: dsalles@fgv.br.

**** Doutor em administração pela Escola Brasileira de Administração Pública e de Empresas da Fundação Getulio Vargas (Ebape/FGV). Professor da Ebape/FGV. Endereço: Praia de Botafogo, 190/sala 502 - CEP 22250-900 — Rio de Janeiro, RJ, Brasil. E-mail: ebrubens@fgv.br.
} 
categorias de valores associados ao trabalho: i) eficácia/eficiência, ii) sistema de gestão organizacional, iii) respeito ao empregado e iv) preferências por recompensa. O procedimento analítico adotado foi o da comparação das distribuições para os grupos, em cada categoria de análise, usando a análise da variância e confirmação pelo teste não paramétrico de Kruskal-Wallis. Foram encontradas diferenças significativas no nível de $5 \%$ apenas para dois itens relacionados à categoria sistema de gestão organizacional (respeito aos níveis de autoridade e à hierarquia, e cumprimento das tarefas dentro dos padrões da organização) para as respostas dos três grupos. Em relação à categoria preferências por recompensa, os resultados contrariam aqueles obtidos por Wittmer (1991) no contexto americano.

\section{Influence of organisational settings on work values and reward preferences} This paper presents results of an exploratory research that aimed at exploring employees' similarities and differences in work-related values in public, private and hybrid organizations in Brazil. Ninety-eight questionnaires were considered from employees (managerial and non-managerial level) of nineteen organizations of the three groups (public, private and hybrid). Drawing on Wittmer (1991) and Tamayo \& Gondim (1996), the research privileged items related to for categories of workrelated values: i) efficacy/efficiency; ii) management system; iii) respect towards employees, and iv) reward preferences. Analytical procedures consisted of distribution comparisons using one-way analysis of variance and Kruskal-Wallis nonparametric test. Except for two items related to management system (hierarchy and professionalism), no significant differences could be found among the three groups (at a 5\% confidence level). Results relating to reward preferences were significantly different from Wittmer's (1991) findings in the American context.

\section{Introdução}

O debate sobre as diferenças e similaridades entre atitudes, preferências por recompensas e valores de empregados de empresas públicas e privadas não é novo. Ao longo das duas últimas décadas, as pesquisas têm se ampliado para incluir organizações que operam na fronteira entre o Estado e o mercado e que precisam combinar racionalidades e orientações culturais conflitantes: as chamadas organizações híbridas (Karré e Ribeiro, 2005).

Essas novas configurações surgem como foco de interesse acadêmico a partir dos anos 1980 - acompanhando as transformações que levaram ao redesenho do setor público e ao expressivo crescimento do chamado terceiro setor. A realidade da multiplicação de organizações híbridas, somada a concepções mais recentes sobre a distinção entre organizações públicas e privadas, que destacam a multidimensionalidade dos conceitos de público e privado (Bozeman, 1987; 
Perry e Rainey, 1988), favorecem o estudo de tipos organizacionais para além da dicotomia organização pública-empresa privada.

Permanece, então, a importância de se explorarem as diferenças e similaridades entre os diversos tipos de organização. As similaridades, se predominam, favorecem a adoção de práticas gerenciais semelhantes, independente da natureza da organização. As diferenças, se confirmadas, têm impacto significativo para as estratégias gerenciais e para arquiteturas organizacionais alternativas.

Portanto, o objetivo deste estudo foi explorar possíveis similaridades e diferenças quanto a valores relacionados ao trabalho e a preferências por recompensa de empregados de organizações públicas, híbridas e privadas no Brasil, com vistas ao levantamento de informações que possam subsidiar a gestão de pessoas em temas como motivação, reconhecimento e recompensa e comprometimento. Nesse sentido, o artigo apresenta os resultados de pesquisa em que foram analisados 98 questionários, de empregados de nível técnico e gerencial, de um total de 19 organizações distribuídas entre os três grupos (públicas, privadas e híbridas).

O referencial teórico do estudo está estruturado sobre dois eixos: o primeiro refere-se às organizações híbridas enquanto categoria analítica relevante no cenário contemporâneo de multiplicidade institucional, fornecendo o quadro conceitual para a compreensão das diferentes configurações organizacionais. O segundo eixo explora os valores e seu vínculo com a motivação e as preferências dos indivíduos no contexto organizacional, subsidiando a compreensão sobre a realidade do comportamento humano nas configurações estudadas nesta pesquisa.

O procedimento de pesquisa consistiu na construção e aplicação de um questionário que considerou as categorias mais significativas encontradas por Tamayo e Gondim (1996) no levantamento sobre valores organizacionais no Brasil, e aquelas propostas por Wittmer (1991) em relação às preferências por recompensas associadas ao trabalho. A partir do trabalho de Wittmer (1991) foram testadas as preferências quanto a: remuneração; realizar um trabalho útil aos outros; segurança; trabalho socialmente relevante; status; respeito dos colegas; amizade com os colegas e obtenção de promoção. Já a partir de Tamayo e Gondim (1991) buscou-se aprofundar o entendimento dos valores dos empregados dos três grupos. Foram considerados itens relativos aos seguintes fatores ou categorias: i) eficácia/eficiência (eficiência; qualidade; produtividade; competência); ii) sistema de gestão organizacional (tradição; hierarquia; postura profissional; organização), iii) respeito ao empregado (respeito; re- 
conhecimento; qualificação dos recursos humanos; plano de carreira; clima organizacional).

O procedimento analítico adotado foi o da comparação das distribuições de preferência, segundo uma escala ordinal, para os grupos, em cada categoria de análise (eficácia/eficiência, sistema de gestão organizacional, respeito ao empregado e preferências por recompensa) usando a análise da variância (one-way analysis of variance) e confirmação pelo teste não paramétrico de Kruskal-Wallis.

Contrariando os resultados obtidos por Wittmer (1991), a pesquisa mostrou haver muito pouca diferença nas respostas dos grupos, indicando considerável homogeneidade intergrupos. Apenas dois itens, dos 20 testados nas quatro categorias analisadas, apresentaram diferença estatística ao nível de significância de $5 \%$ entre os grupos de organizações privadas, públicas e híbridas. Esse nível de significância foi mantido com vistas a facilitar a comparação com os resultados obtidos por Wittmer (1991).

\section{Organizações: públicas, privadas e híbridas}

Comparações entre o setor público e o setor privado têm sido objeto da atenção continuada de teóricos e pesquisadores. Como destacam Rainey e Bozeman (2000), embora não haja sequer consenso sobre a real significância da distinção público-privado, a tendência das pesquisas é considerá-la a priori. Um corpo de pesquisas significativo vem se acumulando ao longo dos anos e muitos tópicos de relevância indiscutível têm sido explorados da perspectiva da diferenciação entre empresas públicas e privadas, tais como valores e atitudes relacionados ao trabalho, complexidade e clareza de objetivos, processo decisório e estrutura organizacional. Nessas pesquisas, as organizações híbridas muitas vezes surgem como que por diferenciação - o que está entre o público e o privado - , estes os focos principais de interesse das pesquisas empíricas e dos esforços teóricos.

Nos últimos 20 anos, transformações sociais e econômicas de vulto levaram, entre outros aspectos, à redefinição do papel do Estado, à expansão do controle social via mercado e ao crescimento expressivo do chamado terceiro setor. No Brasil, como em outros países, o processo de redemocratização, as mudanças econômicas e as reformas do aparelho de Estado contribuíram fortemente para a formação do cenário de pluralidade institucional, que traz em seu bojo diferentes possibilidades de participação dos atores sociais e a multiplicidade de formas organizacionais, tanto públicas como privadas (Imasato 
et al., 2008; Paula, 2005). Esse quadro favoreceu o surgimento de concepções teóricas que enfatizam a multidimensionalidade dos conceitos de público e privado (Bozeman, 1987; Perry e Rainey, 1988), em contraposição a abordagens dicotômicas.

Bozeman (1987) e Perry e Rainey (1988) sustentam que a preocupação apenas com as categorias pública e privada não só representa uma limitação teórica e prática para o avanço do conhecimento sobre a realidade organizacional, mas também uma miopia em relação às variações no ambiente institucional e econômico. Para esses autores, o progresso no desenvolvimento de teorias e pesquisas empíricas reside na capacidade de explorar os mecanismos de controle institucional do ambiente externo e relacioná-los à dinâmica e às propriedades organizacionais, uma vez que todos os processos essenciais das organizações são influenciados por esses mecanismos: estabelecimento e manutenção da organização; estruturação; aquisição e gerenciamento de recursos; estabelecimento de objetivos e a busca por alcançá-los (Bozeman, 1987).

O termo "híbrido" tem sido empregado em diferentes contextos no campo da administração: para se referir a estruturas que combinam elementos de diferentes tipos organizacionais (Alves, 2004), para se referir à aplicação simultânea de estratégias de negócio diversas (Medeiros e Antunes, 2008; Moraes e Zilber, 2004) ou à combinação de formas de governança corporativa (Joldersma e Winter, 2002). No entanto, o termo é predominantemente utilizado para se referir a organizações que combinam características das organizações públicas e privadas - organizações que combinam racionalidades, propriedades e orientações de domínios estabelecidos como distintos: Estado e mercado.

Assim, é preciso avançar na elaboração da distinção entre público e privado para incluir os mecanismos de controle social sobre as atividades organizacionais e as diferentes configurações que essa interação produz. Ao mesmo tempo, deve-se ter em mente que o ambiente organizacional é um sistema complexo em que convergem forças individuais, interpessoais, ambientais, sociais e econômicas. A multiplicação de tipos organizacionais, resultante das transformações da sociedade, apresenta novos questionamentos para a pesquisa empírica, para os esforços teóricos e para a prática da gestão: a diferenciação organizacional é capaz de gerar ambientes organizacionais distintos? Estamos diante de diferenças significativas nos processos organizacionais, exigindo novas lógicas de gestão? Novas configurações organizacionais são capazes de gerar contextos que representem uma transformação nos vínculos dos indivíduos com o trabalho? Que marcos gerenciais as novas configurações exigem, especialmente no setor público? 


\subsection{Propriedade, fonte de recursos e modos de controle social}

Diversos pesquisadores (Hickson et al., 1986; Chubb e Moe, 1985) definem organizações públicas como aquelas de propriedade do governo, sejam elas órgãos da administração pública, hospitais ou empresas estatais. A ideia por trás dessa abordagem é de que a propriedade pública impõe à organização controles institucionais governamentais, em vez do controle econômico dos mercados. No entanto, essa abordagem não leva em conta, por exemplo, que regulação ou contratos com o governo podem impor forte controle governamental sobre organizações privadas. Da mesma forma, organizações governamentais financiadas por vendas ou taxas ao consumidor podem conquistar significativa autonomia em relação aos controles do Estado (Perry e Rainey, 1988).

Para tratar essas limitações, alguns autores incorporam à propriedade (ownership) a fonte de recursos (funding) como critério para definição de organizações públicas e privadas (Wamsley e Zald, 1973; Fottler, 1981). São públicas organizações de propriedade governamental financiadas pelo governo, e são privadas organizações de propriedade privada financiadas por vendas ou doações privadas. Nessa abordagem, organizações que apresentam concomitantemente características das organizações públicas e das organizações privadas (por exemplo, propriedade privada e fonte de recursos pública) representam tipos mistos: organizações híbridas.

Segundo Perry e Rainey (1988), propriedade e fonte de recursos constituem as dimensões mais comuns de diferenciação entre organizações públicas e privadas nos estudos de organizações. Propriedade e fonte de recursos são características organizacionais relativamente claras, e refletem, até certo ponto, o tipo de controle externo a que a organização está submetida. No entanto, ambas podem assumir diferentes formas e apresentar inter-relações complexas com o ambiente institucional e com as estruturas de mercado. Os autores propõem, então, que se avance no entendimento das variações nos controles ambientais e suas interações com as características organizacionais.

Dahl e Lindblom (1953), em uma das primeiras abordagens teóricas relacionando organizações e economia política, postulam que existem dois modos de controle social fundamentais: as atividades econômicas podem ser dirigidas por uma hierarquia politicamente constituída e com uma estrutura de poder pluralística (poliarquia), ou conduzidas de maneira relativamente descentralizada, com formas organizacionais autônomas e controladas basicamente via sistema de preços nos mercados econômicos. Poliarquia e mercado representam dois extremos de um continuum, e esses modos de controle na prática se sobrepõem e se combinam. A distinção entre poliarquias e merca- 
dos também corresponde a uma distinção entre controle social via autoridade governamental e via trocas econômicas (Lindblom, 1977). Aos extremos das formas de controle social correspondem duas configurações organizacionais: agências (agencies) e empresas (enterprises).

Nas sociedades contemporâneas, o exercício do controle social é pluralístico: o controle da autoridade governamental é exercido por múltiplas agências, grupos de interesse são mobilizados, diversos atores interagem e exercem pressão no jogo de forças do processo político. A esse cenário de pluralidade institucional correspondem formas organizacionais que se afastam dos "tipos puros" das agências e das empresas controladas exclusivamente pelos mecanismos econômicos dos mercados. Como aponta Thoenig (2007:13) "desenhos institucionais híbridos e estatutos legais vagos são prática comum": agências públicas operam em termos próximos aos de mercado, por vezes até competindo com empresas privadas; autoridades governamentais alocam fundos públicos em organizações sem fins lucrativos, que obtêm boa parte de seus recursos do Estado; entidades não governamentais fornecem bens coletivos sem disporem de mandato formal para tal.

As organizações híbridas surgem, então, como resposta ao mesmo tempo adaptativa e criativa para exploração de possibilidades de ação num quadro em que fronteiras, papéis e racionalidades tipicamente "públicas" e "privadas" não constituem a regra.

Perry e Rainey (1988) propõem uma tipologia de organizações, baseada nas dimensões: propriedade, fonte principal de recursos e modo de controle social. Essa tipologia relaciona diferentes configurações a mecanismos institucionais de controle social, combinando as contribuições dos trabalhos de Dahl e Lindblom (1953), Lindblom (1977) e Wamsley e Zald (1973).

O cruzamento das dimensões propriedade, fonte principal de recursos e modo de controle social gera a tipologia de organizações apresentada no Quadro 1:

Quadro 1

Tipologia das organizações de Perry e Rainey

\begin{tabular}{|lccc|}
\hline Tipo de organização & Propriedade & $\begin{array}{l}\text { Fonte de } \\
\text { recursos }\end{array}$ & $\begin{array}{c}\text { Modo de controle } \\
\text { social }\end{array}$ \\
\hline $\begin{array}{l}\text { Órgão do governo } \\
\text { (Bureau) } \\
\begin{array}{l}\text { Corporação pública } \\
\text { (Government Corporation) }\end{array}\end{array}$ pública & pública & Poliarquia \\
\hline
\end{tabular}




\begin{tabular}{|lccc|}
\hline Tipo de organização & Propriedade & $\begin{array}{c}\text { Fonte de } \\
\text { recursos }\end{array}$ & $\begin{array}{c}\text { Modo de controle } \\
\text { social }\end{array}$ \\
\hline $\begin{array}{l}\text { Empresa patrocinada pelo governo } \\
\text { (Government Sponsored Enterprise) }\end{array}$ & privada & pública & Poliarquia \\
$\begin{array}{l}\text { Empresa regulada } \\
\text { (Regulated Enterprise) }\end{array}$ & privada & privada & Poliarquia \\
$\begin{array}{l}\text { Empresa governamental } \\
\text { (Governmental Enterprise) }\end{array}$ & pública & pública & Mercado \\
$\begin{array}{l}\text { Empresa estatal } \\
\text { (State-Owned Enterprise) }\end{array}$ & pública & privada & Mercado \\
$\begin{array}{l}\text { Fornecedores de bens e serviços ao governo } \\
\text { (Government Contractor) }\end{array}$ & privada & pública & Mercado \\
$\begin{array}{l}\text { Empresa privada } \\
\text { (Private Enterprise) }\end{array}$ & privada & privada & Mercado \\
\hline
\end{tabular}

Fonte: Perry e Rainey (1988)

Cabe reconhecer que a pluralidade institucional que produz a multiplicidade de configurações e que conforma a atuação das organizações é apoiada, em última instância, sobre um conjunto de relações sociais e humanas que transforma a vida organizacional contemporânea, como apontado por ThiryCherques (2007:720):

O que faz funcionar as organizações contemporâneas e dá vida aos mercados econômicos não é nem a rígida disciplina estatal nem a abstrata lei econômica da oferta e da procura, mas a cadeia de dependências e relações de confiança de que são feitas as redes [...]; em que, sob os termos como /empresa/, /agência/, /órgão/, seja em que regime econômico for, existe uma pluralidade de formas de organizar e de modos de trabalhar, de estruturas e de valores. Um momento em que a vida organizacional não é só dada pela circulação de bens, mas também por pessoas, símbolos e valores; em que as transações são complexas e as formas e modos de trabalhar, praticamente infinitos.

Este artigo partiu do seguinte questionamento: existe diferença nos valores e preferências dos indivíduos que atuam em contextos organizacionais distintos? Como apontado, as diferenças - se significativas - demandam o desenvolvimento de estratégias e práticas organizacionais alternativas, favorecendo a inovação na gestão.

Deve-se destacar que essa pergunta não é nova e tem sido explorada com o foco na dicotomia organização pública-empresa privada, especialmente 
na literatura americana. No que se refere à consideração de tipos híbridos de organização, bem como ao contexto não americano, porém, o corpo de pesquisas é bastante escasso e se apresenta como amplo campo a ser estudado.

Visando aprofundar a reflexão sobre a complexidade dos anseios humanos nas organizações, discutem-se, a seguir, possíveis relações entre valores, motivos e preferências por recompensas.

\section{Valores, motivos e preferências}

A percepção da organização encontra-se relacionada aos aspectos avaliativos e de julgamento exercidos no seu ambiente, presentes na interação entre o indivíduo e o seu trabalho. De acordo com Dejours (2002), o julgamento do trabalho do indivíduo pela organização pode funcionar, no registro da subjetividade, como reconhecimento pelo outro. Esse reconhecimento refere-se tanto à qualidade do trabalho como à contribuição à gestão e ao desenvolvimento organizacional. De acordo com esse enfoque, reconhecimento pode significar a retribuição moral-simbólica dada ao indivíduo, como compensação por sua contribuição, por meio do engajamento e comprometimento de sua subjetividade e inteligência, à eficácia da organização. Essa percepção implica, na organização, a noção de julgamento que recai sobre o reconhecimento e, em consequência, sobre as perspectivas de realização do indivíduo, ou seja, no seu sentimento de pertencimento e identificação com os valores organizacionais.

Valores podem ser definidos como critérios ou metas que transcendem situações específicas, que são ordenados por sua importância e que servem como princípios orientadores da vida dos indivíduos (Schwartz, 1999). Os valores são representações cognitivas de necessidades e motivos, e "o que diferencia um valor de outro é o tipo de motivação que ele expressa" (Tamayo, 2007:18).

Os valores contêm um elemento de julgamento baseado em posições individuais sobre o que é correto, bom e desejável. De modo geral, são estáveis ao longo do tempo. Os valores, adquiridos pelas experiências de vida dos indivíduos, compõem o seu sistema de atitudes e norteiam seus comportamentos (Lewis, 1991; Rokeach, 1981; Schwartz, 1999; Tamayo et al., 2000).

Como destacam Tamayo e Paschoal (2003), no processo motivacional os valores fornecem a representação cognitiva responsável pela atribuição de significado cultural e cognitivo às necessidades, transformando-as em intenções e metas. 
Assim, os valores individuais no contexto do trabalho expressam necessidades que irão manifestar-se na natureza motivacional do indivíduo, nos interesses que guiam sua ação organizacional. Deve-se esperar que estejam relacionados à dinâmica do trabalho e às possibilidades de recompensa que a vida organizacional pode oferecer.

A motivação dos indivíduos em ambientes de trabalho é a base sobre a qual os sistemas de recompensas são construídos. Tais sistemas são concebidos a partir de premissas e crenças sobre os fatores determinantes da motivação no ambiente de trabalho, direcionando as ações gerenciais para a aplicação dos melhores incentivos e, consequentemente, para a obtenção da maior produtividade. No entanto, como os significados desses incentivos diferem entre os indivíduos, a generalização não é aplicável. Diferentes fatores motivacionais podem representar reconhecimento, status e poder, dependendo, além de questões intrínsecas ao indivíduo, da influência de fatores externos, tais como a cultura organizacional, o contexto econômico e social, entre outros.

Há, ainda, a presunção de que as pessoas mais comprometidas são mais motivadas a permanecer na organização e a se empenhar na realização de suas atividades, em sintonia com os objetivos organizacionais (Meyer e Allen, 1998; Meyer, 1997). A crença subjacente é a de que o comprometimento dos indivíduos induz efeitos positivos para a eficácia das organizações em que trabalham, levando-os até mesmo a suportarem condições de trabalho altamente exigentes (Rego, 2002). É a imagem do "vestir a camisa" da organização. Este fato tem sua origem nos laços emocionais do indivíduo com a organização, representados pela lealdade, pelo apego, pela confiança.

A vida organizacional contemporânea é marcada pela transformação nos vínculos entre indivíduos e organizações. Em lugar da lealdade, da adesão às normas e das expectativas de longo prazo, típicas da organização burocrática, o novo contrato psicológico de trabalho entre indivíduo e organização é fundado sobre relações mais efêmeras e voltado ao cálculo da contribuição que as partes aportam aos respectivos desenvolvimentos (Van Buren III, 2003).

Ao mesmo tempo, mudanças nos mercados e nas estruturas produtivas levam à adoção de práticas mais flexíveis de trabalho, que exigem, dos recursos humanos, que mobilizem um conjunto de disposições específicas, traduzidas em atitudes "proativas", "orientadas ao mercado" e "empreendedoras" (Du Gay, Salaman e Rees, 1996). Uma vez que o trabalho nas organizações "carrega a marca, a identidade do trabalhador" (Thiry-Cherques, 2007:723), 
aspectos relacionados a valores, subjetividade, expectativas e preferências tornam-se fundamentais para garantir o desempenho adequado.

Apesar do reconhecimento do vínculo entre valores e preferências dos indivíduos com a motivação e o comprometimento e, consequentemente, com o próprio desempenho organizacional, e da realidade da fragmentação e multiplicidade de tipos organizacionais, levantamento realizado nas principais revistas, journals e bases de dados da área de administração permitiu encontrar apenas quatro textos que buscam explorar os valores e preferências dos empregados considerando o tipo de organização como fator interveniente, além da dicotomia organização pública-organização privada: Falcone (1991); Lan e Rainey (1992); Steinhaus \&ePerry (1996) Wittmer (1991).

Comparando empresas públicas, privadas e híbridas, Falcone (1991) mostrou que a satisfação no trabalho varia entre gerentes dos três grupos, com os gerentes de empresas públicas apresentando nível de satisfação abaixo dos demais. $\mathrm{O}$ estudo também mostrou que para gerentes de organizações públicas e híbridas a satisfação no trabalho está significativamente relacionada à capacidade de "fazer diferença".

Lan e Rainey (1992) mostram que a percepção dos gerentes é diferente nos três tipos de organização no que concerne à ênfase nos procedimentos e regras, com as organizações híbridas numa posição intermediária entre as organizações privadas e as públicas.

Steinhaus e Perry (1996), estudando o comprometimento organizacional, não encontraram diferenças entre os três tipos de organização. Os resultados sustentam a tese de que comprometimento organizacional está relacionado mais a fatores ligados ao ambiente de trabalho, como autonomia, satisfação e relacionamento com os colegas, do que com o tipo ou setor a que a organização pertence.

Wittmer (1991), em estudo comparativo de referência sobre organizações públicas, privadas e híbridas, encontrou diferenças e similaridades entre os gerentes dos três grupos no que se refere a preferências de reconhecimento e recompensa. Para uma amostra de 220 questionários (62 de privadas, 92 de públicas, 66 de híbridas), o estudo apontou que gerentes de empresas privadas têm maior propensão a serem motivados por prêmios monetários ( $1^{\mathrm{a}}$ posição no ranking de preferências) do que seus pares nas empresas públicas e híbridas ( $3^{a}$ posição em ambos os grupos), que são mais motivados por fazer um trabalho útil para os outros (1 $1^{a}$ posição para os dois grupos). Além desses, mais três fatores de motivação apresentaram diferenças significativas para os grupos: ter oportunidade de fazer um trabalho socialmente relevante, status e segurança no emprego. No entanto, alguns fatores de motivação relacionados 
ao trabalho e à organização (respeito dos colegas, promoção e amizade com os colegas) não são significativamente diferentes para os três grupos. É digno de nota que o item respeito dos colegas ocupa a segunda posição em importância em todos os grupos.

Em seu conjunto, os resultados de pesquisa ainda são bastante limitados e não conclusivos. A escassez de estudos comparativos entre organizações públicas, privadas e híbridas em investigações que subsidiem o entendimento dos múltiplos vínculos entre indivíduos e organizações aponta a necessidade de se avançar na investigação dos valores, expectativas e preferências dos profissionais em relação ao trabalho. Ao testar o estudo de Wittmer (1991) no contexto de organizações brasileiras, pretendeu-se contribuir para a sistematização do conhecimento na área, pela aplicação de um instrumento já reconhecido por estudos anteriores. Ao mesmo tempo, ao se incluir na pesquisa conjunto selecionado de categorias e itens propostos por Tamayo e Gondim (1996), buscou-se avançar o conhecimento de forma original, utilizando fatores que refletem pesquisa extensiva sobre valores realizada no Brasil.

\section{A pesquisa}

No presente estudo foram comparados: órgãos do governo, empresas privadas e, compondo o grupo das organizações híbridas, organizações do Sistema SEBRAE (Serviço Brasileiro de Apoio às Micro e Pequenas Empresas), do Sistema Indústria (Confederação Nacional da Indústria - CNI, Serviço Social da Indústria - Sesi, Serviço Nacional de Aprendizagem Industrial - Senai e Instituto Euvaldo Lodi - IEL) e do Sistema Comércio (Confederação Nacional do Comércio - CNC, Serviço Social do Comércio - Sesc, Serviço Nacional de Aprendizagem Comercial - Senac). Estas são organizações privadas que têm como fonte principal e histórica de recursos contribuições compulsórias, estabelecidas e garantidas em lei (contribuição sobre a folha de pagamento, contribuição sindical). Segundo a tipologia anteriormente apresentada, podem ser classificadas como empresas patrocinadas pelo governo.

Baseados na lógica da propriedade privada e financiados a partir de recursos públicos, esses sistemas se caracterizam como organizações híbridas. Estão sujeitos, portanto, a um conjunto misto de cobranças e orientações para resultados que se não se conformam à lógica de lucro do setor privado, tampouco apresentam restrições legais e descontinuidade de objetivos típicas do setor público. 


\subsection{Metodologia e tratamento dos dados}

Foram incluídos na amostragem empregados dos três conjuntos de organizações, adotando-se o critério não amostral da acessibilidade, baseado na técnica de amostragem do tipo bola-de-neve. Segundo essa técnica, um grupo aleatório é inicialmente escolhido e solicita-se a estes que indiquem outros que pertençam à mesma população-alvo (Malhotra, 2001). Apesar das limitações quanto à não aleatoriedade da amostra, essa técnica facilita o acesso, de forma ágil, ao grupo de interesse. Assim, foram identificados e contatados, inicialmente, servidores e empregados de organizações públicas, privadas e híbridas, e encaminhados questionários a servidores e empregados dessas organizações, solicitando a cada um que, por sua vez, encaminhasse o questionário a até 10 colegas de trabalho na mesma organização.

Na coleta buscou-se um equilíbrio na representatividade dos três grupos foco do estudo, mas não para a distribuição interna; no setor público, por exemplo, houve organizações que retornaram apenas um questionário, enquanto outras retornaram nove questionários. Importante destacar que, diferentemente da pesquisa de Wittmer (1991), foram considerados não apenas gerentes, mas também empregados com cargos de supervisão e técnicos, o que pode contribuir para divergências nos resultados dos dois trabalhos, como discutido na conclusão.

No modelo originalmente utilizado por Wittmer (1991), as variáveis de interesse eram relacionadas à categoria "preferências por recompensa". Na presente pesquisa, além dessa categoria, foram incluídas mais três outras categorias de valores relacionados ao trabalho: eficácia/eficiência, sistema de gestão organizacional e respeito ao empregado - tomando como base a análise de valores originada do trabalho de Tamayo e Gondim (1996).

Em seu estudo, Tamayo e Gondim (1996) consideraram uma lista de 48 valores organizacionais que, após aplicados em pesquisa de campo, foram agrupados em cinco fatores, extraídos por estes autores com base em análise fatorial, cada qual incorporando entre quatro e 10 valores. Para esta pesquisa, foram considerados apenas os fatores e respectivos valores mais aderentes ao escopo da análise pretendida; não foram considerados aqueles relativos à categoria "gestão e inovação". Dessa forma, foram considerados apenas quatro itens de cada fator, com vistas a reduzir o tamanho do questionário a ser aplicado e manter a validade de face das categorias. 
Para cada uma dessas quatro categorias de análise foi proposta uma questão, com respectivamente, 4, 4, 4 e 8 afirmativas, para que os respondentes as ordenassem de acordo com a importância, pessoal e particular, atribuída aos itens apresentados. Um formulário inicial foi aplicado, como pré-teste, a um grupo de 10 respondentes com formação até $2^{\circ}$ Grau completo, antes da definição do formulário final.

$\mathrm{Na}$ aplicação final do questionário, o processo de coleta durou quatro meses, de dezembro de 2007 a março de 2008. Retornaram 100 questionários, sendo dois eliminados por falhas no preenchimento, totalizando 98 questionários válidos, de um total de 190 encaminhados. Os respondentes estavam vinculados a um total de 19 organizações, de natureza pública, privada e híbrida, sendo, como já assinalado, variável o número de respondentes para cada organização.

As tabelas 1,2 e 3 a seguir apresentam a distribuição das respostas pelos tipos de organização, formação dos respondentes, tempo no cargo ocupado e tempo na organização:

Tabela 1

Respostas por tipo de organização

\begin{tabular}{|lcc|}
\hline Válidos & Frequência & Percentual \\
\hline Pública & 25 & 25,5 \\
Privada & 31 & 31,6 \\
Híbrida & 42 & 42,9 \\
Total & 98 & 100,0 \\
\hline
\end{tabular}

Tabela 2

Formação (agregado)

\begin{tabular}{|llccc|}
\hline & Frequência & Percentual & $\begin{array}{c}\text { Percentual } \\
\text { válido }\end{array}$ \\
\hline Válidos & Pós-graduação & 76 & 77,6 & 78,4 \\
& Superior completo & 16 & 16,3 & 16,5 \\
& 2o Grau completo & 5 & 5,1 & 5,2 \\
& Total & 97 & 99,0 & 100,0 \\
Missing & & 1 & 1,0 & \\
Total & & 98 & 100,0 & \\
\hline
\end{tabular}


Tabela 3

Tempo na organização e tempo no cargo

\begin{tabular}{|lrrc|}
\hline & & Tempo org. & Tempo cargo \\
\hline N & Válidos & 96 & 96 \\
& Missing & 2 & 2 \\
Média & & 9,5521 & 3,2083 \\
Mediana & 7,0000 & 2,0000 \\
Moda &, 00 &, 00 \\
Desvio Padrão & 8,81 & 3,81 \\
Mínimo &, 00 &, 00 \\
Máximo & 43,00 & 20,00 \\
\hline
\end{tabular}

O teste Anova realizado para as variáveis tempo na organização, tempo no cargo, e formação não apontou diferenças significativas entre os três grupos, como apresentado na Tabela 4, indicando uma homogeneidade da amostra.

Tabela 4

Resultados teste Anova

\begin{tabular}{|c|c|c|c|c|c|}
\hline & \multicolumn{3}{|c|}{ MÉDIAS } & \multirow[b]{2}{*}{$\mathrm{F}$} & \multirow[b]{2}{*}{ Sig } \\
\hline & $\begin{array}{l}\text { Pública } \\
(\mathrm{N}=24)\end{array}$ & $\begin{array}{l}\text { Privada } \\
(\mathrm{N}=30)\end{array}$ & $\begin{array}{l}\text { Híbrida } \\
(\mathrm{N}=42)\end{array}$ & & \\
\hline Tempo org. & 11,63 & 11,07 & 7,29 & 2,58 & 0,081 \\
\hline Tempo cargo & 4,38 & 2,60 & 2,98 & 1,6 & 0,207 \\
\hline Formação & 1,42 & 1,13 & 1,29 & 1,925 & 0,152 \\
\hline
\end{tabular}

Cabe observar que a informação sobre a formação dos respondentes foi composta segundo escala categórica tal que: (1) Pós-graduação, (2) Superior completo, (3) 2ำ Grau completo, e (4) 1ํGrau completo. Naturalmente, há restrições em processar análises de média para dados categóricos, que no caso serviu principalmente para compatibilizar com a metodologia original de Wittmer (1991). Apesar dessa restrição, é possível observar que quanto menor a média para a formação, ou seja, mais próxima a 1 , maior o nível de escolaridade associado à composição do grupo.

O procedimento analítico adotado seguiu também o utilizado por Wittmer (1991), qual seja, comparação das distribuições para os grupos, em cada categoria de análise, usando a análise da variância (one-way analysis of va- 
riance) e, dada a natureza ordinal das escalas, confirmação pelo teste não paramétrico de Kruskal-Wallis. Os procedimentos estatísticos foram realizados no software SPSS versão 12.

Foram comparadas inicialmente as médias dos postos atribuídos aos itens relativos a cada tipo de organização e segundo a categoria específica, e verificada a existência de diferenças significativas segundo o teste paramétrico da Anova ou não paramétrico Kuskal-Wallis ao nível de 5\%, o mesmo adotado por Wittmer (1991).

Os resultados desses testes são apresentados e discutidos na seção que se segue.

\subsection{Resultados}

Os resultados obtidos retratam valores e preferências dos empregados de organizações, que servem como subsídio para a ação organizacional no que tange a políticas de motivação, engajamento e comprometimento dos profissionais no contexto brasileiro.

Os resultados mostraram haver muito pouca diferença entre os grupos. Exceto para dois itens da questão 2, dispostos na Tabela 6, não há nenhuma diferença significativa, ao nível de $5 \%$, entre as respostas dos grupos público, privado e híbrido. Nessa questão 2, os itens (b) Respeito aos níveis de autoridade e à hierarquia ("hierarquia") e (c) Cumprimento das tarefas dentro dos padrões da organização ("postura profissional") foram os únicos que apresentaram, por ambos os testes, diferenças significativas entre os grupos, ao nível de $5 \%$.

Esses resultados apontam diferenças diante daqueles obtidos anteriormente por Wittmer (1991) junto a gerentes nos Estados Unidos. Embora com as limitações desta pesquisa - amostra reduzida, modelo amostral baseado na técnica bola-de-neve e inclusão na amostra de técnicos, e não apenas gerentes - , as análises dos dados apontam que não há evidências que o setor da organização (público, privado ou híbrido), no caso brasileiro, seja importante para explicar as diferenças dos grupos em termos de preferências por recompensa, o que pode ensejar diversas hipóteses, tratadas na conclusão.

$\mathrm{Na}$ categoria dos valores relacionados a eficácia/eficiência (Tabela 5), os resultados revelam a convergência das preocupações dos empregados, de todos os grupos, com o alcance de seus objetivos e metas e o desenvolvimento profissional. O foco prioritário é o próprio indivíduo; a preocupação com a organização (aprimoramento dos bens e serviços e utilização eficiente de 
recursos) ocupa as últimas posições. Esse ordenamento parece refletir discursos e práticas organizacionais correntes, como o reconhecimento baseado no desempenho e empregabilidade.

Tabela 5

Análise da variância dos rankings de eficácia/eficiência por tipo de organização - Questão 1

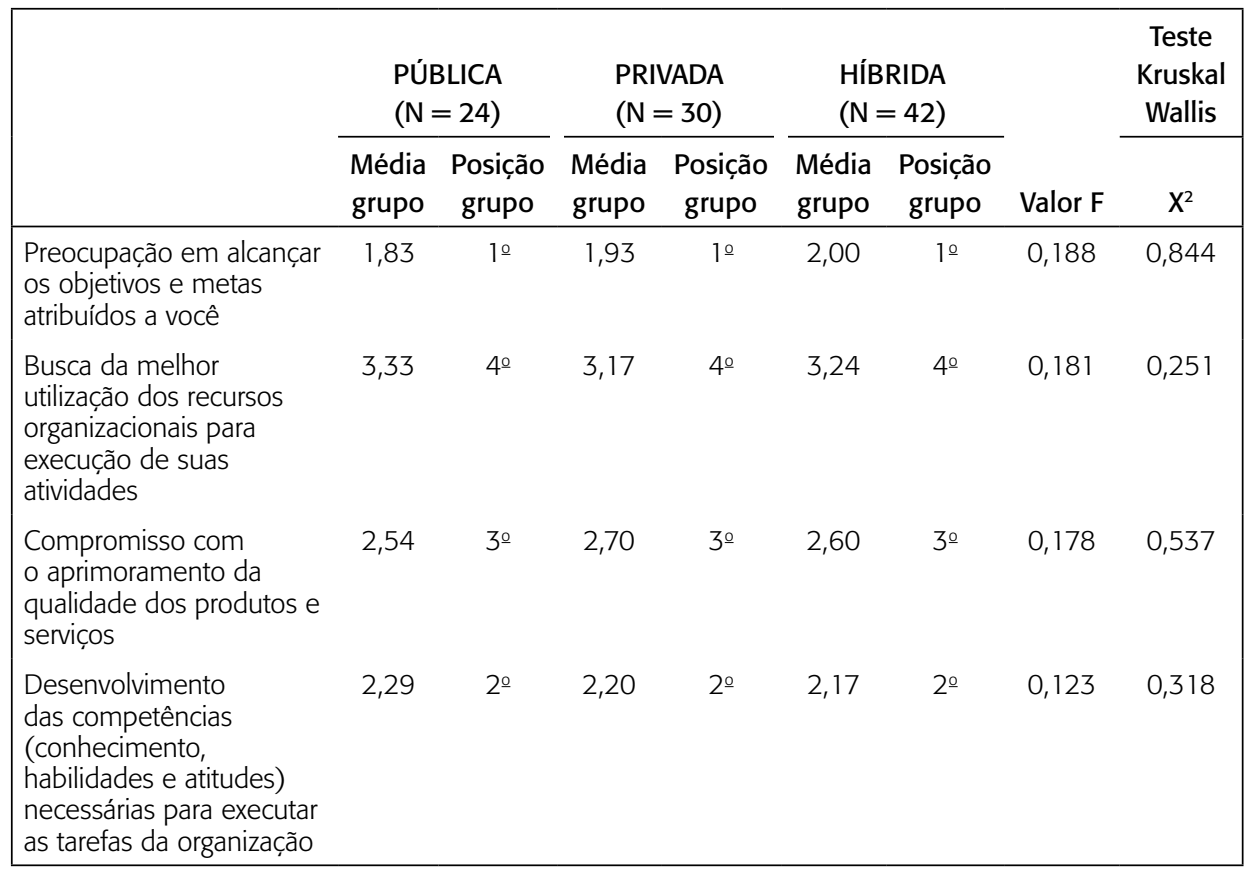

A categoria sistema de gestão organizacional (Tabela 6) foi a única que apresentou diferenças significativas nas médias das respostas, especificamente aquelas atribuídas aos itens "respeito aos níveis de autoridade e à hierarquia" e "cumprimento das tarefas dentro dos padrões da organização". Nesses itens, o setor é importante para explicar as diferenças nas respostas entre os grupos. No entanto, no ranking dos três grupos o item relativo ao cumprimento das tarefas dentro dos padrões da organização ocupa o primeiro lugar. Isso reforça a ascensão de valores mais ligados ao desempenho nas relações de trabalho, em detrimento da valorização das tradições e costumes da organização - item que ocupa a última posição.

O item "Cumprimento das tarefas dentro dos padrões da organização", embora tenha apresentando diferenças entre os grupos, permaneceu como o 
mais importante para os participantes dos três tipos de organização. O mesmo não ocorreu, contudo, com "Respeito aos níveis de autoridade e à hierarquia". É possível supor que essa maior necessidade de aderência aos princípios formais de autoridade nas organizações híbridas seja uma resposta à ambiguidade de objetivos e governança que enfrentam ao se situarem entre o mercado e a administração pública.

\section{Tabela 6}

Análise da variância dos rankings de sistema de gestão organizacional por tipo de organização - Questão 2

\begin{tabular}{|c|c|c|c|c|c|c|c|c|}
\hline & \multicolumn{2}{|c|}{$\begin{array}{l}\text { PÚBLICA } \\
(\mathrm{N}=24)\end{array}$} & \multicolumn{2}{|c|}{$\begin{array}{r}\text { PRIVADA } \\
(\mathrm{N}=30)\end{array}$} & \multicolumn{2}{|c|}{$\begin{array}{l}\text { HÍBRIDA } \\
(\mathrm{N}=42)\end{array}$} & \multirow[b]{2}{*}{ Valor F } & \multirow{2}{*}{$\begin{array}{c}\begin{array}{c}\text { Teste } \\
\text { Kruskal } \\
\text { Wallis }\end{array} \\
X^{2}\end{array}$} \\
\hline & $\begin{array}{l}\text { Média } \\
\text { grupo }\end{array}$ & $\begin{array}{l}\text { Posição } \\
\text { grupo }\end{array}$ & $\begin{array}{l}\text { Média } \\
\text { grupo }\end{array}$ & $\begin{array}{l}\text { Posição } \\
\text { grupo }\end{array}$ & $\begin{array}{l}\text { Média } \\
\text { grupo }\end{array}$ & $\begin{array}{l}\text { Posição } \\
\text { grupo }\end{array}$ & & \\
\hline $\begin{array}{l}\text { Respeito às tradições e } \\
\text { costumes da organização }\end{array}$ & 3,67 & 40 & 3,13 & 40 & 3,33 & 40 & 2,689 & 5,07 \\
\hline $\begin{array}{l}\text { Respeito aos níveis de } \\
\text { autoridade e à hierarquia }\end{array}$ & 2,50 & 30 & 2,90 & 30 & 2,19 & $2^{\circ}$ & $4,051 *$ & $7,59 *$ \\
\hline $\begin{array}{l}\text { Cumprimento das tarefas } \\
\text { dentro dos padrões da } \\
\text { organização }\end{array}$ & 1,67 & 10 & 1,63 & 10 & 2,12 & 10 & $3,775^{*}$ & $6,18^{*}$ \\
\hline $\begin{array}{l}\text { Existência de normas } \\
\text { e objetivos claros e } \\
\text { explícitos }\end{array}$ & 2,17 & $2^{\circ}$ & 2,33 & $2^{\circ}$ & 2,36 & 30 & 0,240 & 0,42 \\
\hline
\end{tabular}

$* p<0.05$

Os resultados da categoria dos valores relacionados ao respeito ao empregado (Tabela 7) confirmam a importância das oportunidades de crescimento e qualificação profissional, bem como a importância de a organização oferecer possibilidades de desenvolvimento da carreira. Deve-se destacar que nesta categoria, os empregados das organizações privadas e híbridas apresentaram o mesmo ranking de preferências, afastando-se um pouco das organizações públicas. No entanto, as diferenças nas respostas, como já apontado, não têm significância estatística. 
Análise da variância dos rankings de respeito ao empregado por tipo de organização - Questão 3

\begin{tabular}{|c|c|c|c|c|c|c|c|c|}
\hline & \multicolumn{2}{|c|}{$\begin{array}{l}\text { PÚBLICA } \\
(\mathrm{N}=24)\end{array}$} & \multicolumn{2}{|c|}{$\begin{array}{l}\text { PRIVADA } \\
(\mathrm{N}=30)\end{array}$} & \multicolumn{2}{|c|}{$\begin{array}{l}\text { HÍBRIDA } \\
(\mathrm{N}=42)\end{array}$} & \multirow[b]{2}{*}{$\begin{array}{c}\text { Valor } \\
\mathrm{F}\end{array}$} & \multirow{2}{*}{$\begin{array}{c}\text { Teste } \\
\text { Kruska } \\
\text { Wallis }\end{array}$} \\
\hline & $\begin{array}{l}\text { Média } \\
\text { grupo }\end{array}$ & $\begin{array}{c}\text { Posição } \\
\text { grupo }\end{array}$ & $\begin{array}{l}\text { Média } \\
\text { grupo }\end{array}$ & $\begin{array}{c}\text { Posição } \\
\text { grupo }\end{array}$ & $\begin{array}{l}\text { Média } \\
\text { grupo }\end{array}$ & $\begin{array}{c}\text { Posição } \\
\text { grupo }\end{array}$ & & \\
\hline $\begin{array}{l}\text { Oportunidade para } \\
\text { compartilhar opiniões e } \\
\text { ideias }\end{array}$ & 2,92 & $4^{\circ}$ & 2,47 & $2^{\circ}$ & 2,93 & $4^{\circ}$ & 1,894 & 3,505 \\
\hline $\begin{array}{l}\text { Valorização do mérito na } \\
\text { realização dos trabalhos }\end{array}$ & 2,75 & 3음 & 2,80 & $4^{\circ}$ & 2,60 & 3음 & 0,342 & 0,436 \\
\hline $\begin{array}{l}\text { Oportunidade de } \\
\text { qualificação e aquisição de } \\
\text { novos conhecimentos e } \\
\text { habilidades }\end{array}$ & 2,08 & 10 & 2,03 & 10 & 2,21 & 10 & 1,504 & 0,533 \\
\hline $\begin{array}{l}\text { Possibilidade de } \\
\text { crescimento na carreira }\end{array}$ & 2,25 & $2^{\circ}$ & 2,70 & 3o & 2,26 & $2^{\circ}$ & 0,228 & 2,72 \\
\hline
\end{tabular}

No que se refere às preferências por recompensa, a Tabela 8 mostra que o respeito dos colegas ocupa o primeiro lugar, para os empregados de todos os grupos, seguido da oportunidade de fazer um trabalho que seja útil aos outros. Esses resultados podem apontar a importância das relações interpessoais como fator de satisfação e motivação, bem como o fato de que o reconhecimento que se espera no ambiente do trabalho não flui apenas dos níveis de chefia nem de "clientes" externos. Ao mesmo tempo, deve-se notar que os itens segurança no emprego, promoção e conquista de status e prestígio ocupam os últimos lugares do ranking. Esses resultados revelam indivíduos cujos valores se distanciam do estereótipo do servidor público que valoriza a segurança acima de tudo, ou do empregado de empresa privada que busca prioritariamente a promoção e o prestígio a curto prazo. Esses resultados reforçam a noção de que os indivíduos, não importa em que tipo de organização estejam, esperam que o trabalho seja fonte de realização pessoal e de reconhecimento, não só de sobrevivência e status. 
Tabela 8

Análise da variância dos rankings de preferências por recompensa por tipo de organização - Questão 4

\begin{tabular}{|c|c|c|c|c|c|c|c|c|}
\hline & \multicolumn{2}{|c|}{$\begin{array}{l}\text { PÚBLICA } \\
(\mathrm{N}=24)\end{array}$} & \multicolumn{2}{|c|}{$\begin{array}{l}\text { PRIVADA } \\
(\mathrm{N}=30)\end{array}$} & \multicolumn{2}{|c|}{$\begin{array}{l}\text { HÍBRIDA } \\
(\mathrm{N}=42)\end{array}$} & \multirow[b]{2}{*}{$\begin{array}{c}\text { Valor } \\
\mathrm{F}\end{array}$} & \multirow{2}{*}{$\begin{array}{c}\begin{array}{c}\text { Teste } \\
\text { Kruskal } \\
\text { Wallis }\end{array} \\
\mathrm{X}^{2}\end{array}$} \\
\hline & $\begin{array}{l}\text { Média } \\
\text { grupo }\end{array}$ & $\begin{array}{l}\text { Posição } \\
\text { grupo }\end{array}$ & $\begin{array}{l}\text { Média } \\
\text { grupo }\end{array}$ & $\begin{array}{l}\text { Posição } \\
\text { grupo }\end{array}$ & $\begin{array}{l}\text { Média } \\
\text { grupo }\end{array}$ & $\begin{array}{l}\text { Posição } \\
\text { grupo }\end{array}$ & & \\
\hline Ganhar mais & 3,92 & 3응 & 4,48 & 40 & 3,71 & 3응 & 1,478 & 3,64 \\
\hline $\begin{array}{l}\text { Fazer um trabalho que seja } \\
\text { útil aos outros }\end{array}$ & 3,48 & $2^{\circ}$ & 2,71 & $2^{\circ}$ & 3,40 & $2^{\circ}$ & 1,215 & 1,736 \\
\hline $\begin{array}{l}\text { Ter a segurança de } \\
\text { permanecer no emprego }\end{array}$ & 5,12 & 60 & 5,35 & 60 & 4,95 & 60 & 0,299 & 0,853 \\
\hline $\begin{array}{l}\text { Ter o respeito dos colegas } \\
\text { pela qualidade do seu } \\
\text { trabalho }\end{array}$ & 2,84 & 10 & 2,16 & 10 & 2,88 & 10 & 1,828 & 4,514 \\
\hline $\begin{array}{l}\text { Cultivar a amizade e as } \\
\text { relaç̃oses cordiais com os } \\
\text { colegas }\end{array}$ & 4,76 & 5 은 & 4,16 & 30 & 4,88 & $5^{\circ}$ & 1,668 & 2,996 \\
\hline $\begin{array}{l}\text { Conquistar status e } \\
\text { prestígio }\end{array}$ & 5,92 & $8^{\circ}$ & 6,68 & $8^{\circ}$ & 6,33 & $8^{\circ}$ & 0,857 & 1,602 \\
\hline Obter promoção & 5,68 & 7으 & 5,35 & 60 & 5,14 & 7으 & 0,685 & 1,221 \\
\hline $\begin{array}{l}\text { Ter oportunidades de fazer } \\
\text { um trabalho socialmente } \\
\text { relevante }\end{array}$ & 4,28 & 40 & 5,10 & 5응 & 4,69 & 40 & 0,84 & 1,448 \\
\hline
\end{tabular}

\section{Conclusões}

Este artigo apresentou resultados de pesquisa que explorou as similaridades e diferenças nos valores relacionados ao trabalho em organizações públicas, privadas e híbridas no Brasil. Foram analisados questionários de 98 trabalhadores, de nível técnico e gerencial, vinculados a 19 organizações participantes da pesquisa, distribuídas entre os três tipos.

Foram explorados 20 itens, de quatro categorias de valores relacionados ao trabalho: i) eficácia/eficiência, ii) sistema de gestão organizacional, iii) respeito ao empregado e iv) preferências por recompensa. Essas categorias foram originadas dos trabalhos de Tamayo e Gondim (1996) e Wittmer (1991). 
Os resultados apontaram que, exceto para dois itens relacionados à categoria sistema de gestão organizacional (hierarquia e postura profissional), não houve diferença significativa nas respostas, ao nível de 5\%, entre os grupos de organizações públicas, privadas e híbridas. Esses resultados não devem ser tomados como definitivos, mas indicam uma homogeneidade nos valores dos indivíduos no contexto do trabalho. Seria preciso testar amostras maiores, com maior heterogeneidade entre os perfis para justificar o uso de variáveis de controle, para identificarmos possíveis diferenças nas respostas entre tipos de organizações ou subgrupos de respondentes.

Pode-se especular, entretanto, se essa homogeneidade é decorrente das próprias transformações institucionais que tornam difusos os limites entre setor público e setor privado, que acabam por favorecer a circulação de informações, discursos e pessoas entre organizações de diversas áreas.

No que tange à categoria preferências por recompensas, os resultados de Wittmer (1991) não foram confirmados para a amostra brasileira. Devese destacar, no entanto, a diferente composição do grupo de respondentes do referido trabalho (apenas gerentes) e a do presente estudo (gerentes e técnicos), bem como o tamanho das respectivas amostras (220 questionários em Wittmer contra 98 do presente estudo). Isso estimula a realizar novos estudos e explorar os motivos pelos quais tais diferenças, no Brasil, não foram significativas. Verificar se outros fatores organizacionais propiciam diferenças em relação a valores e preferências por recompensas poderá, também, ser um caminho para futuras pesquisas.

O conhecimento sobre o terreno em que a prática tem lugar é fator essencial para a ação organizacional efetiva. Com esta pesquisa, buscou-se contribuir com informações que aprimorem o conhecimento sobre a realidade de indivíduos e organizações, particularmente apontando eventuais divergências com realidades de outros países. Embora realizada no contexto brasileiro, os resultados permitem destacar pontos de atenção para pesquisadores situados em cenários que partilhem de práticas culturais e sociais se não semelhantes, ao menos irmanadas na distância da realidade americana. Seria relevante que estudos futuros possam considerar variáveis culturais e sociais das organizações em seus contextos diversos, de modo a buscar um entendimento mais abrangente do objeto de interesse deste estudo, uma vez que nas análises realizadas a natureza da organização e sua relação com as variáveis foi considerada de forma abrangente. Assim, desdobramentos de pesquisa que considerassem outras dimensões, como tempo de existência da organização (como possível proxy para consolidação da cultura organizacional), e outras variáveis típicas dos estudos de cultura organizacional, como as utilizadas por Hofstede et al. (1990). 
Retomando o objetivo proposto neste texto, de explorar relações entre tipos de organizações e predominância de valores relacionados ao trabalho e preferências por recompensa dos empregados, é instigante observar que, apesar das diferenças nas características das organizações públicas, híbridas e privadas, a natureza da motivação, como expectativa de recompensa, e a base valorativa de seus trabalhadores sejam tão similares. Essa observação pode trazer reflexões e alimentar futuras pesquisas sobre a relação entre grandes mudanças na sociedade e a transformação de valores e práticas organizacionais.

\section{Referências}

ALVES, S. A hibridez da estrutura em duas grandes empresas: uma abordagem analítica multidimensional. In: ENCONTRO NACIONAL DOS PROGRAMAS DE PÓS-GRADUAÇÃO EM ADMINISTRAÇÃO — ENANPAD, 28., Curitiba. Anais... Curitiba: Anpad, 2004.

APPEL, Z.; PUCCI, V. Comportamento pessoal versus comportamento organizacional. Psicología para América Latina, n. 9, abr. 2007.

BOZEMAN, B. All organizations are public. San Francisco: Jossey-Bass, 1987.

CHUBB, J.E.; MOE, T.M. Politics, markets, and the organization of schools. Artigo apresentado ao American Political Science Association Annual Meeting, New Orleans, 1985.

DAHL, R.A.; LINDBLOM, C.E. Politics, economics and welfare. New York: Harper \& Brothers, 1953.

DAWES, R.; SMITH, T. Attitude and opinion measurement. In: LINDZEY, G.; ARONSON, E. Handbook of social psychology. 3. ed. New York: Random House, 1985.

DEJOURS, C. O fator humano. Rio de Janeiro: Fundação Getulio Vargas, 2002.

DuGAY, P.; SALAMAN, G.; REES, B. The conduct of management and the management of conduct: contemporary managerial discourse and the constitution of the 'competent' manager. Journal of Management Studies, v. 33, n. 3, 1996.

FALCONE, S. SELF-ASSESMENTS AND JOB SATISFACTION IN PUBLIC AND PRIVATE ORGANIZATIONS. Public Productivity \& Management Review, v. 14, n. 4, p. 385-396, 1991.

FOTTLER, M.D. Management: is it really generic? Academy of Management Review, v. 6, n. 1, p. 1-12, 1981.

HICKSON, D.J. et al. Top decisions: strategic decision-making in organizations. San Francisco: Jossey-Bass, 1986. 
HOFSTEDE, G. et al. Measuring organizational cultures: a qualitative and quantitative study across twenty cases. Administrative Science Quarterly, v. 35, n. 2, p. 286-316, Jun. 1990.

IMASATO, T.; MARTINS, P.E.M.; PIERANTI, O.P. Administrative reforms and hybridization: a challenge for the analysis of public organizations in the era of globalization. In: LATIN AMERICAN AND EUROPEAN MEETING ON ORGANIZATIONAL STUDIES - LAEMOS COLLOQUIUM, 2., Rio de Janeiro. Anais... Rio de Janeiro: FGV, 2008.

JOLDERSMA, C.; WINTER, V. Strategic management in hybrid organizations. Public Management Review, v. 4, n. 1, 2002.

KARRÉ, P.M.; RIBEIRO, T.C. The 'social' profit of hybrid service delivery. Artigo apresentado à European Group of Public Administration Conference - EGPA, Berna, 2005. Disponível em <www.hybridorganisations.com/publications/thesocial-profit-of-hybrid-service-delivery>. Acesso em: 22 out. 2007.

LAN, Z.; RAINEY, H.G. Goals, rules, and effectiveness in public, private, and hybrid organizations: more evidence on frequent assertions about differences. Journal of Public Administration Research and Theory, v. 2, n. 1, p. 5-28, Jan. 1992.

LEWIS, H. A question of values: six ways we make the personal choices that shape our lives. New York: Harper Collins, 1991.

LINDBLOM, C.E. Politics and markets. New York: Basic Books, 1977.

MALHOTRA, N.K. Pesquisa de marketing: uma orientação aplicada. Porto Alegre: Bookman, 2001.

MCGUIRE, W. Attitudes and attitude change. In: LINDZEY, G.; ARONSON, E. Handbook of social psychology. 3. ed. New York: Random House, 1985.

MEDEIROS, J.J.; ANTUNES, E.A. The impact of internal and external complexity on strategy and on strategic process. In: LATIN AMERICAN AND EUROPEAN MEETING ON ORGANIZATIONAL STUDIES - LAEMOS COLLOQUIUM, 2., Rio de Janeiro. Anais... Rio de Janeiro: FGV, 2008.

MEYER, J. P. Organizational commitment. In: COOPER, C.L.; ROBERTSON, I.T. (Eds.). International Review of Industrial and Organizational Psychology, v. 12, p. 175-228, 1997.

MEYER, J.P.; ALLEN, N.J. A three-component conceptualization of organization commitment. Human Resource Management Review, v. 1, p. 61-98, 1991.

MORAES, C.A.; ZILBER, M.A. Perfil estratégico do setor petroquímico brasileiro. In: ENCONTRO NACIONAL DOS PROGRAMAS DE PÓS-GRADUAÇÃO EM ADMINISTRAÇÃO — ENANPAD, 28., Curitiba. Anais... Curitiba: Anpad, 2004. 
PAULA, A.P.P. Administração pública brasileira entre o gerencialismo e a gestão social. Revista de Administração de Empresas, v. 45, n. 1, jan./mar. 2005.

PERRY, J.L.; RAINEY, H.G. The public-private distinction in organization theory: a critique and research strategy. The Academy of Management Review, v. 13, n. 2, p. 182-201, 1988.

RAINEY, H.G.; BOZEMAN, B. Comparing public and private organizations: empirical research and the power of the a priori. Journal of Public Administration Research and Theory, v. 10, n. 2, p. 447-469, Apr. 2000.

REGO, A. Comprometimento afetivo dos membros organizacionais: o papel das percepções de justiça. Revista de Administração Contemporânea, v. 6, n. 2, p. 209241, 2002.

ROKEACH, M. Crenças, atitudes e valores. Rio de Janeiro: Interciência, 1981.

SCHWARTZ, S. H. A theory of cultural values and some implications for work. Applied Psychology: An International Review, v. 48, n. 1, p. 23-47, Jan. 1999.

STEINHAUS, C.S.; PERRY, J.L. Organizational commitment: does sector matter? Public Productivity \& Management Review, v. 19, n. 3, p. 278-288, 1996.

TAMAYO, A. Contribuições ao estudo dos valores pessoais, laborais e organizacionais. Psicologia: Teoria e Pesquisa, v. 23, n. especial, p. 17-24, 2007.

.; GONDIM, M.G.C. Escala de valores organizacionais. RAUSP, v. 31, n. 2, p. 62-72, abr.-jun., 1996.

.; MENDES, A.; PAZ, M.G. Inventário de valores organizacionais. Estudos de Psicologia, v. 5, n. 2, p. 289-315, maio/ago. 2000.

.; PASCHOAL, T. A relação da motivação para o trabalho com as metas do trabalhador. Revista de Administração Contemporânea, v. 7, n. 2, p. 33-54, 2003.

THIRY-CHERQUES, H.R. O trabalho individualizado: da venda à dádiva. Revista de Administração Pública, v. 41, n. 4, p. 9-36, jul./ago. 2007.

THOENIG, J.C. Recuperando a ênfase na dimensão pública dos estudos organizacionais. Revista de Administração Pública, ed. especial comemorativa, p. 9-36, 2007.

VAN BUREN III, H. J. Boundaryles careers and employability obligations. Business Ethics Quarterly, v. 13, n. 2, p. 131-149, Apr./Jun. 2003.

WAMSLEY, G.L.; ZALD, M.N. The political economy of public organizations. Lexington: Lexington, 1973.

WITTMER, D. Serving the people or serving for pay: reward preferences among government, hybrid sector, and business managers. Public Productivity \& Management Review, v. 14, n. 4, p. 369-374, Summer 1991. 